\title{
Overcommitment to work is associated with vital exhaustion
}

\section{Journal Article}

\section{Author(s):}

Preckel, Daniel; Känel, Roland von; Kudielka, Brigitte M.; Fischer, Joachim E.

Publication date:

2005-03

Permanent link:

https://doi.org/10.3929/ethz-b-000032944

\section{Rights / license:}

In Copyright - Non-Commercial Use Permitted

\section{Originally published in:}

International Archives of Occupational and Environmental Health 78(2), https://doi.org/10.1007/s00420-004-0572-8 


\section{Daniel Preckel $\cdot$ Roland von Känel \\ Brigitte M. Kudielka · Joachim E. Fischer \\ Overcommitment to work is associated with vital exhaustion}

Received: 7 January 2004/ Accepted: 8 September 2004/Published online: 22 February 2005

(C) Springer-Verlag 2005

\begin{abstract}
Objectives: Vital exhaustion has been shown to predict the progression and manifestation of cardiovascular disease. Little is known about the relationship between vital exhaustion and overcommitment, the inability to withdraw from obligations at work. The aim of this study was to explore the relationship between vital exhaustion and overcommitment at work, as measured by the intrinsic-effort scale of the effort-reward model after consideration of other potentially salutogenetic and pathogenetic working conditions. Methods: This cross-sectional study is based on a stratified random sample of 634 employees (mean age 39.9 years, standard deviation 10.7 years) from a manufacturing and assembly plant for aeroplane parts. Participants completed a questionnaire, which included the nine-item shortened Maastricht exhaustion questionnaire to score the dependent variable exhaustion, and the six-item short form of the intrinsic-effort scale ("immersion") of the effort-reward-imbalance model as the primary independent variable. Perceived work stress was assessed by Siegrist's effort-reward-imbalance questionnaire and the 52-item, 13 subscale salutogenetic subjective work assessment (SALSA) questionnaire, which focuses on indicators of perceived work stress in terms of pathogenetic and salutogenetic descriptors of decision latitude, psychological job demands, and social support. Additional candidate covariates included depression, anxiety and type-D personality. Results: In regression analysis, overcommitment $(r=0.516 ; P<0.0001)$ was independently associated with vital exhaustion. Multivariable linear regression analysis showed that overcommitment explained $27 \%$ of the variance of vital exhaustion. Conclusions: Overcommitment, indicating an exhaustive work-related coping style, is indepen-
\end{abstract}

D. Preckel · R. Känel · B. M. Kudielka · J. E. Fischer ( ()

Swiss Federal Institute of Technology (ETH),

Institute for Behavioral Sciences,

Turnerstrasse 1, 8092 Zurich, Switzerland

E-mail: fischer@ifv.gess.ethz.ch

Tel.: + 41-1-63222743

Fax: + 41-1-6321219 dently associated with vital exhaustion. It appears to be an important personality trait that may contribute to feelings of exhaustion at times of increased job strain.

Keywords Vital exhaustion - Overcommitment . Effort-reward-imbalance $\cdot$ Job stress $\cdot$ Cardiovascular disease

\section{Introduction}

The concept of vital exhaustion was introduced by Appels and co-workers to describe a psychological state characterized by excessive fatigue and lack of energy, demoralization, and increased irritability (Appels 1990, 1997). Vital exhaustion has been identified as an independent risk factor for adverse health outcomes, including coronary artery disease (CAD) (Kop et al. 1998). Excess fatigue and feelings of general malaise are among the most prevalent precursors of myocardial infarction and sudden cardiac death (Appels and Mulder 1988; Cole et al. 1999; Kop et al. 1994). Vital exhaustion is also associated with depression (Kopp et al. 1998; Raikkonen et al. 1996; van Diest and Appels 1991), type-D personality (Denollet 2000; Schmidt Pedersen and Middel 2001), and with perceived work stress (Schnorpfeil et al. 2002). Our group has previously suggested that vital exhaustion should be considered as an indicator of the breakdown of adaptation to a chronically stressful working environment. However, the question as to what extent an individual's intrinsic disposition contributes to the risk of exhaustion was left unanswered in our previous work (Schnorpfeil et al. 2002).

Intrinsic components related to the individual pattern of coping with job demands were included in the effortreward-imbalance model suggested by Siegrist and co-workers. Providing a conceptual framework, the model was introduced to explain the relation between work characteristics and adverse health outcomes in 
empirical research (de Jonge et al. 2000; Siegrist 2002). The model posits that a lack of reciprocity between costs and gains causes a state of emotional distress that, in the long run, may augment the risk of cardiovascular disease and other adverse health outcomes, such as psychosomatic complaints (de Jonge et al. 2000). The model distinguishes between situational ('extrinsic') and personal ('intrinsic') components. Extrinsic components include the rewards received at work, offered to a worker as part of the social exchange process, such as money, esteem, security or career opportunities. Psychological and physical demands at work are also understood to be of extrinsic quality. In contrast, the intrinsic or personal component 'overcommitment' stands for a specific, individual pattern of coping with the various job demands and eliciting rewards.

The term overcommitment defines a set of attitudes, behaviours and emotions that reflect a person's excessive striving for approval and appreciation. The model proposes that people who overcommit are exaggerating their efforts beyond levels usually considered appropriate, or that they expose themselves to high demands at work too often. Consequently, these efforts diminish their potential to recover from job demands and increase their susceptibility to frustration when the expected rewards are not forthcoming, which eventually results in poor health (Siegrist 2001). In support of the effort-reward-imbalance model, cross-sectional studies have demonstrated that overcommitment is associated with self-reported musculoskeletal pain (Joksimovic et al. 2002), depression (Tsutsumi et al. 2001) and cardiovascular risk factors (Vrijkotte et al. 1999).

The aim of the present study was to test the unique value of Siegrist's effort-reward-imbalance model (Siegrist et al. 1997) in predicting vital exhaustion independently of other psychosocial risk factors for cardiovascular disease previously associated with vital exhaustion, namely type-D personality (Denollet 2000) and depressed mood (Kopp et al. 1998, van Diest and Appels 1991). Additional explanatory factors, such as pathogenetic and salutogenetic work characteristics (Schnorpfeil et al. 2002), were included. In order to adjust for possible confounding effects, we took into account, in multivariate regression analyses, age, gender, educational level, family status, shift work, and job position.

\section{Methods}

\section{Settings and participants}

In November 2002 a stratified, representative, random sample of 1,117 employees from two European aircraft manufacturing plants was invited to participate in a research project termed "Health and Work". Of these employees, $816(73 \%)$ agreed to participate. No incentive was offered, but time during participation was paid for as working time. If required, personal feedback was given by two study physicians. Subjects with a positive history of CAD and cardiac surgery were excluded. The final sample consisted of 642 participants $(90 \%$ male) with a complete data set of the variables of interest for allowing the full linear regression approach. Mean age of the sample was 39.9 years (SD 10.7 years). Mean employment time at the current plant was 15.4 (SD 11.4) years. Shift work was carried out by $29.3 \%$ of the participants. Further characteristics of the sample are given in Table 1.

\section{Study design}

The study was of cross-sectional design. During a 1-h group session (10-25 individuals), each participant completed a set of questionnaires after a standardized oral introduction. Group sessions were held in a room detached from the working environment.

\section{Measurements}

\section{Vital exhaustion}

Vital exhaustion was assessed by means of the nine-item short form of the Maastricht vital exhaustion questionnaire, which was derived from the original Maastricht questionnaire established by Appels et al. (1987) and Appels and Mulder (1989). The nine items asked about were: undue fatigue, trouble falling asleep, waking up at night, general malaise, apathy, irritability, loss of energy, demoralization and waking up exhausted. For the purpose of this study the nine items were translated into the German language in cooperation with the

Table 1 Characteristics of the study population

\begin{tabular}{lll}
\hline Characteristic & $\begin{array}{l}\text { Number } \\
\text { (SD) }\end{array}$ & Percentage \\
\hline $\begin{array}{ll}\text { Number of participants } \\
\text { Gender (men/women) }\end{array}$ & 642 & \\
Mean age (SD) in years & $575 / 67$ & $89.6 / 10.4$ \\
Mean duration (SD) & $39.86(10.73)$ \\
of employment in years & $15.43(11.41)$ \\
Shift work & \multicolumn{2}{l}{} \\
Position & 188 & 29.3 \\
Supervisor or manager & 29 & 4.5 \\
Foreman & 95 & 14.8 \\
Skilled workers & 458 & 71.3 \\
Semi-skilled workers & 25 & 3.9 \\
Trainees & 35 & 5.5 \\
Educational level & \multicolumn{2}{l}{} \\
Primary school & 9 & 1.4 \\
Lower secondary level & 399 & 62.1 \\
Intermediate secondary level & 144 & 22.4 \\
Vocational college/higher secondary level 90 & 14.0 \\
Family status & \multicolumn{2}{l}{} \\
Single & 190 & 29.6 \\
Married & 416 & 64.8 \\
Divorced & 35 & 5.5 \\
Widowed & 1 & 0.2 \\
\hline
\end{tabular}


authors of the original questionnaire (Schnorpfeil et al. 2002). In either version of the original or the translated questionnaire, possible categories are "no", scored as 0; "don't know", scored as 1; and "yes", scored as 2, which add up to an overall score of from 0 to 18 .

\section{Effort-reward}

Extrinsic effort and reward at work are the main scales of the model of effort-reward imbalance by Siegrist and co-workers (Siegrist 2002). Extrinsic effort is measured by six items that refer to demanding aspects of the work environment. Items are answered in two steps. First, subjects agree or disagree on whether or not the item content describes a typical experience of their work situation. Subsequently, subjects who agreed on one item are asked to evaluate to what extent they usually feel distressed by this experience. The rating procedure is defined as follows: 1 = "does not apply", $2=$ "does apply but not distressed", $3=$ "does apply and somewhat distressed", $4=$ "does apply and distressed", 5= "does apply and very distressed". Reward is measured accordingly for effort by 11 items, although the coding is reversed. Therefore, the lower the summary score for reward, the lower the subjectively experienced reward at work and the higher the ratings of distress due to low reward. The ratio of effort (numerator) and reward (denominator) quantifies the amount of effort-reward imbalance.

\section{Overcommitment}

Overcommitment at work was assessed with the six-item short form of the intrinsic-effort scale ("immersion") of the effort-reward model (Siegrist 2002). On a four-point rating scale subjects indicated to what extent they personally agreed or disagreed with the given statements. The short form focuses on "inability to withdraw from work" (five items) and "disproportionate irritability" (one item). The appendix lists the items of the overcommitment scale.

\section{Work characteristics}

The conditions of the working environment were assessed by the salutogenetic subjective work assessment (SALSA) (Rimann and Udris 1997). The SALSA questionnaire assesses the subjective perception of work characteristics. This instrument has been validated on German industrial workers with a cultural background similar to that of the target population. Based on the 52 items of the SALSA the following 13 scales are derived: wholeness of work tasks (three items), responsibility and required qualification (four items), task variety (three items), qualification potential (three items), decision authority (three items), extent of participation (three items), excessive workload or qualitative demands (five items), lack of qualitative demands (three items), social support of co-workers (four items), supportive supervi- sor behaviour (four items), adverse co-worker behaviour (three items), adverse supervisor behaviour (three items) and adverse physical work conditions (11 items). Conceptually, the SALSA scales comprise pathogenetic and salutogenetic descriptors of decision latitude, psychological job demands, and social support given by supervisors and co-workers.

\section{Depressed mood}

Depressed mood was measured by the depression subscale of the hospital anxiety and depression scale (HADS), a 14-item, self-report, screening tool originally developed to measure the severity of anxious and depressed mood (Zigmond and Snaith 1983). The HADS avoids statements that refer to symptoms that might have a physical cause (e.g. weight loss, insomnia). The depression subscale of the HADS (HADS-D) consists of seven items. Answers are coded on a four-point Likert scale ranging from $0=$ "mostly" to $3=$ "not at all". We applied the recently validated German version (Herrmann-Lingen et al. 2002).

\section{Type-D (distressed) personality questionnaire (DS14)}

We used the type-D personality questionnaire to assess the subjects' tendency to experience distress (Denollet and Brutsaert 1998; Denollet and Van Heck 2001). From this concept the combination of high negative affectivity and high social inhibition designates a type-D personality. Negative affectivity is defined as the tendency to experience aversive emotional states (dysphoria, depressed mood) and feelings of tension and worry. Social inhibition is defined by the tendency to inhibit self-expression in social interaction (reticence and withdrawal). Negative affectivity is associated with vulnerability to clinically relevant depression and anxiety, and social inhibition with interpersonal stress. We applied the German version, recently validated by HerrmannLingen and co-workers (2002). According this version, the two subscales, negative affectivity and social inhibition, are composed of seven items, each and subjects' responses are coded on a five-point rating scale ranging from 0 to 4 .

\section{Statistical analysis}

The data analyses are based on those participants who provided a complete data set in terms of the variables: vital exhaustion, age, gender, education level, family status, position, shift work, type-D personality, depression, overcommitment, effort-reward, and SALSA variables. As the first step, the potential association between vital exhaustion, effort-reward imbalance and overcommitment was analysed by partial correlation analyses that accounted for baseline demographic variables and risk factors for vital exhaustion (e.g. type-D 
personality, depression). Secondly, we applied stepwise multivariable regression models, with vital exhaustion score as the dependent variable and overcommitment and effort-reward-imbalance scores as independent variables. Type-D personality, depressed mood, and work characteristics, as measured by the SALSA questionnaire, were included as candidate confounders. Variables that showed no significant associations $(P>0.05)$ with vital exhaustion in univariate analyses (Spearman) were excluded from the multivariate approach. All analyses were performed with SPSS version 11.0 (SPSS, Chicago, Ill., USA).

\section{Results}

From previous criteria (Schnorpfeil et al. 2002), 140 $(21.8 \%)$ subjects in that sample were classified as not being exhausted (vital exhaustion scores between 0 and 2), $311(52.3 \%)$ subjects were mildly to moderately exhausted (vital exhaustion scores between 3 and 10) and $191(25.9 \%)$ subjects showed severe (i.e. "clinical") exhaustion (vital exhaustion scores $\geq 11$ ).

Relation between the vital exhaustion score and effortreward and overcommitment

Firstly, we tested bivariate associations between vital exhaustion and demographic and psychosocial factors. Table 2 shows that the majority of these correlations were statistically significant. The highest correlation coefficients emerged in the associations between vital exhaustion and type-D personality $(r=0.57)$, depression $(r=0.57)$, excessive workload $(r=0.37)$, adverse co-worker behaviour $(r=0.40)$, adverse physical conditions $(r=0.34)$ and, of particular interest, overcommitment $(r=0.52)$ and effort-reward imbalance $(r=0.45)$. Correlation analyses, adjusted for demographic variables and type-D personality and depressed mood, rendered essentially the same results.

\section{Multivariable regression models}

Sequential linear regression analyses contained six independent variables, which, together, explained 52\% of the observed variance of vital exhaustion. Namely, these variables were depression, overcommitment, typeD personality, decision authority, effort-reward imbalance and adverse physical conditions. Effort-reward imbalance and overcommitment were entered in a final step. When overcommitment was entered as the first variable, this scale explained $27 \%$ of the variance in vital exhaustion scores. When overcommitment was added as the last variable in the fully adjusted model, it still explained an additional $4 \%$ variance in vital exhaustion. Table 3 shows the results of the multivariable model.

\section{Discussion}

Overcommitment has been defined as a personality trait characterized by the inability to disengage oneself,
Table 2 Unadjusted and adjusted bivariate correlation analyses between vital exhaustion and work characteristics

\begin{tabular}{|c|c|c|c|c|}
\hline \multirow{2}{*}{$\begin{array}{l}\text { Vital exhaustion } \\
\text { Variable }\end{array}$} & \multicolumn{2}{|c|}{$\begin{array}{l}\text { Simple Pearson } \\
\text { correlation }\end{array}$} & \multicolumn{2}{|c|}{$\begin{array}{l}\text { Partial correlation } \\
\text { controlling for } \\
\text { variables } 1-8\end{array}$} \\
\hline & & & & \\
\hline (1) Age & 0.074 & $P=0.060$ & & \\
\hline (2) Gender & -0.049 & $P=0.212$ & & \\
\hline (3) Education level & -0.095 & $P=0.016$ & & \\
\hline (4) Family status & 0.039 & $P=0.329$ & & \\
\hline (5) Position & 0.002 & $P=0.955$ & & \\
\hline (6) Shift work & 0.124 & $P=0.002$ & & \\
\hline (7) Type-D personality & 0.574 & $P<0.001$ & & \\
\hline (8) Depression (HADS) & 0.574 & $P<0.001$ & & \\
\hline (9) Overcommitment & 0.516 & $P<0.001$ & 0.384 & $P<0.001$ \\
\hline $\begin{array}{l}\text { (10) Effort-reward imbalance } \\
\text { (11) SALSA subscales: }\end{array}$ & 0.453 & $P<0.001$ & 0.547 & $P<0.001$ \\
\hline Wholeness of working task & -0.141 & $P<0.001$ & -0.140 & $P<0.001$ \\
\hline Responsibility, required qualification & -0.086 & $P=0.030$ & -0.067 & $P=0.092$ \\
\hline Task variety & -0.145 & $P<0.001$ & -0.128 & $P=0.001$ \\
\hline Qualification potential & -0.251 & $P<0.001$ & -0.214 & $P<0.001$ \\
\hline Decision authority & -0.169 & $P<0.001$ & -0.15 & $P<0.001$ \\
\hline Extent of participation & -0.302 & $P<0.001$ & -0.278 & $P<0.001$ \\
\hline Excessive workload, qualitative demands & 0.369 & $P<0.001$ & 0.373 & $P<0.001$ \\
\hline Lack of qualitative demands & 0.204 & $P<0.001$ & 0.193 & $P<0.001$ \\
\hline Social support by co-workers & -0.256 & $P<0.001$ & -0.249 & $P<0.001$ \\
\hline Supportive supervisor behaviour & -0.298 & $P<0.001$ & -0.276 & $P<0.001$ \\
\hline Adverse co-worker behaviour & 0.399 & $P<0.001$ & 0.401 & $P<0.001$ \\
\hline Adverse supervisor behaviour & 0.319 & $P<0.001$ & 0.305 & $P<0.001$ \\
\hline Adverse physical conditions & 0.339 & $P<0.001$ & 0.316 & $P<0.001$ \\
\hline
\end{tabular}


Table 3 Final model of multivariable linear regression analyses for vital exhaustion. ERI effort-reward imbalance (ratio)

\begin{tabular}{llll}
\hline Model summary & & & \\
\hline Sequential regression analysis & $\beta$ & $P$ & $r^{2}$ change \\
\hline Type-D personality & 0.297 & 0.001 & 0.33 \\
Overcommitment & 0.263 & 0.001 & 0.11 \\
Depression (HADS-D) & 0.230 & 0.001 & 0.05 \\
SALSA decision authority & -0.107 & 0.001 & 0.02 \\
Effort-reward imbalance & 0.088 & 0.010 & 0.01 \\
Adverse physical conditions & 0.078 & 0.013 & 0.005 \\
& & & 0.518 \\
\hline Total model & & & Adjusted \\
\hline & & & 0.518
\end{tabular}

cognitively, emotionally, and behaviourally, from obligations imposed by the work environment. The present study suggests that overcommitment at work is associated with vital exhaustion, a mental state that has been shown to predict events of cardiovascular disease (Appels and Mulder 1988; Cole et al. 1999; Kop et al. 1994). Notably, the association between overcommitment and exhaustion was independent of type-D personality and severity of depressed mood, which were both found to be correlates of vital exhaustion in previous studies (Wojciechowski et al. 2000; Pedersen and Middel 2001). Other work characteristics (i.e. decision authority, effort-reward imbalance, shift work), although independently associated with exhaustion in our study, only partially moderated the relation between overcommitment and vital exhaustion. While overcommitment may be of an advantage in coping with adverse work characteristics by leading to adaptation to the stressful situation, it may become maladaptive if it confers a rigid coping style that fails to bring relief from job strain.

It has previously been suggested that overcommitment shows a close overlap with the type-A coronary behaviour pattern (Vrijkotte et al. 1999). Type-A individuals exhibit personality features characterized by excessive drive, competitiveness, rapid work pace, and the inability to relax (Friedman and Rosenman 1959). In the early 1980s an independent review panel approved type-A behaviour to be a risk factor for CAD (The Review Panel on Coronary-Prone Behavior and Coronary Heart Disease 1981). However, subsequent studies largely failed to find such a relationship, and, to date, there remains little evidence that type-A personality is an independent risk factor for CAD (Hemingway and Marmot 1999). In spite of this dampened enthusiasm in type-A research, the call for a refinement of the type-A construct (Williams 1987) has burgeoned into an impressive amount of literature on anger and hostile personality traits, which are now both viewed as the "toxic" components of type-A personality (Rozanski et al. 1999). In this light, overcommitment might be another "toxic" ingredient of the type-A personality. Indeed, various characteristics of job stress have been related to increased risk of cardiac disease (Bosma et al. 1997); Hemingway and Marmot 1999).

Our findings ultimately relate to health prevention at the work place. More precisely, intervention strategies may be derived from the acknowledgement of the association between overcommitment and exhaustion, before a state of vital exhaustion occurs. Individuals who commit themselves to work demands in a disproportionate manner might benefit from cognitive-behaviour therapy at an early stage of perceived job strain. Preventive intervention might assist people to adopt more favourable coping patterns when exposed to stressful work circumstances, as well as to reflect on the ideas and assumptions that drive overcommitment. While a certain degree of overcommitment is welcomed from the supervisors' or business owners' perspective, our data suggest that this personal trait puts the individual at an increased risk of exhaustion and, possibly, burnout. Thus, human resource management should be particularly aware of signs that herald exhaustion in their overcommitted staff, because, otherwise, it might spiral into a full burnout syndrome.

The primary limitation of our study is the cross-sectional nature of the data, which do not permit causal conclusions to be drawn with regard to the direction of the overcommitment-exhaustion relationship. However, it appears unlikely that exhaustion would cause individuals to exhibit exaggerated commitment at work. It is more likely that overcommitment renders individuals more susceptible to exhaustion. A further limitation relates to the dearth of longitudinal data that elucidate the biological pathways that link overcommitment to adverse health outcomes. Hence, the assessment of the long-term impact of the overcommitment-exhaustion pathway requires longitudinal studies. One of the strengths of this study is the rather extensive list of independent variables considered that describe work characteristics and personality traits that have been related to adverse health outcomes in the past (e.g. type-D personality). Thus, it is unlikely that relevant variables, that would have unravelled the observed association between exhaustion and overcommitment, remained unconsidered.

Summarizing our findings, we demonstrated that a personal style to cope with adverse work characteristics, namely overcommitment, is independently associated with vital exhaustion. This extends our previous work based on the same population (Schnorpfeil et al. 2002) that demonstrated an association between work characteristics and exhaustion. We suggest that the six-item overcommitment scale is used as a screening instrument in future assessments of work characteristics and employee health.

Acknowledgements This work was supported by grants from the Swiss Federal Institute of Technology and the EADS GmbH, Werk Augsburg, Germany. 


\section{Appendix}

Short version of the overcommitment questionnaire

Please indicate to what extent you personally agree or disagree with the following statements

$(1=$ strongly disagree, $2=$ disagree, $3=$ agree,

$4=$ strongly agree)

\begin{tabular}{ll}
\hline No. & Item \\
\hline 1 & I get easily overwhelmed by time pressures at work \\
2 & I start thinking about work problems as soon \\
& as I get up in the morning \\
3 & When I get home, I can easily relax and forget \\
4 & all about work \\
5 & People close to me say I sacrifice too much for my job \\
6 & Work is usually still on my mind when I go to bed \\
& If I put off something that needs to be done today, \\
\hline
\end{tabular}

\section{References}

Appels A (1990) Mental precursors of myocardial infarction. Br J Psychiatry 156:465-471

Appels A (1997) Why do imminent victims of a cardiac event feel so tired? Int J Clin Pract 51:447-450

Appels A, Mulder P (1988) Excess fatigue as a precursor of myocardial infarction. Eur Heart J 9:758-764

Appels A, Mulder P (1989) Fatigue and heart disease. The association between 'vital exhaustion' and past, present and future coronary heart disease. J Psychosom Res 33:727

Appels A, Hoppener P, Mulder P (1987) A questionnaire to assess premonitory symptoms of myocardial infarction. Int $\mathrm{J}$ Cardiol $17: 15-24$

Bosma H, de Jonge J, Marmot M (1997) Low job control and risk of coronary heart disease in Whitehall II (prospective cohort) study. BMJ 314:558-565

Cole SR, Kawachi I, Sesso HD, Paffenbarger RS, Lee IM (1999) Sense of exhaustion and coronary heart disease among college alumni. Am J Cardiol 84:1401-1405

Denollet J (2000) Type-D personality: a potential risk factor refined. J Psychosom Res 49:255-266

Denollet J, Brutsaert DL (1998) Personality, disease severity, and the risk of long-term cardiac events in patients with a decreased ejection fraction after myocardial infarction. Circulation 92:167-173

Denollet J, Van Heck GL (2001) Psychological risk factors in heart disease: what type-D personality is (not) about. J Psychosom Res 51:465-468

van Diest R, Appels A (1991) Vital exhaustion and depression: a conceptual study. J Psychosom Res 35:535-544

Friedman M, Rosenman R (1959) Association of specific overt behavior pattern with blood and cardiovascular findings. JAMA 169:1286-1296

Hemingway H, Marmot M (1999) Psychosocial factors in the aetiology and prognosis of coronary heart disease: systematic review of prospective cohort studies. BMJ 318:1460-1467

Herrmann-Lingen C, Grande G, Jordan J, Denollet J (2002) Die deutsche DS14: Ein kurzes Selbstbeurteilungsverfahren zur Erfassung des prognoserelevanten "distressed personality type" (Typ D). Psychother Psychosom Med Psychol 52:92
Joksimovic L, Starke D, von dem Knesenbeck O, Siegrist J (2002) Perceived work stress, overcommitment and self-reported musculoskeletal pain: a cross-sectional investigation. Int $\mathbf{J}$ Behav Med 9:122-138

de Jonge J, Bosma H, Peter R, Siegrist J (2000) Job strain, effortreward imbalance and employee well-being: a large-scale crosssectional study. Soc Sci Med 50:1317-1327

Kop WJ, Appels AP, Mendes de Leon CF, de Swart HB, Bar FW (1994) Vital exhaustion predicts new cardiac events after successful coronary angioplasty. Psychosom Med 56:281-287

Kop WJ, Hamulyak K, Pernot C, Appels A (1998) Relationship of blood coagulation and fibrinolysis to vital exhaustion. Psychosom Med 60:352-358

Kopp MS, Falger PR, Appels A, Szedmak S (1998) Depressive symptomatology and vital exhaustion are differentially related to behavioral risk factors for coronary artery disease. Psychosom Med 60:752-758

Pedersen S, Middel B (2001) Increased vital exhaustion among type-D patients with ischemic heart disease. J Psychosom Res $51: 443-449$

Raikkonen K, Lassila R, Keltikangas-Jarvinen L, Hautanen A (1996) Association of chronic stress with plasminogen activator inhibitor-1 in healthy middle-aged men. Arterioscler Thromb Vasc Biol 16:363-367

Rimann M, Udris I, (1997) Subjektive Arbeitsanalyse: Der Fragebogen SALSA. In: Strohm O (eds) Unternehmen arbeitspsychologisch bewerten. vdf Hochschulverlag, Zürich

Rozanski A, Blumenthal JA, Kaplan JR (1999) Impact of psychological factors on the pathogenesis of cardiovascular disease and implications for therapy. Circulation 99:2192-2217

Schmidt Pedersen S, Middel B (2001) Increased vital exhaustion among type-D patients with ischemic heart disease. J Psychosom Res 51:443-449

Schnorpfeil P, Noll A, Wirtz P, Schulze R, Ehlert U, Frey K, Fischer JE (2002) Assessment of exhaustion and related risk factors in employees in the manufacturing industry - a crosssectional study. Int Arch Occup Environ Health 75:535-540

Siegrist J (2001) A theory of occupational stress. In: Dunham J (ed) Stress in the workplace: past, present and future. Whurr, London, pp 52-66

Siegrist J (2002) Effort-reward imbalance at work and health. In: Perrewé PL, Ganster DC (eds) Historical and current perspectives on stress and health. JAI Elsevier, New York, pp 261-292

Siegrist J, Klein D, Voigt KH (1997) Linking sociological with physiological data: the model of effort-reward imbalance at work. Acta Physiol Scand Suppl 640:112-116

The Review Panel on Coronary-Prone Behavior and Coronary Heart Disease (1981) Coronary-prone behavior and coronary heart disease: a critical review. Circulation 63:1199-1215

Tsutsumi A, Kayaba K, Theorell T, Siegrist J (2001) Association between job stress and depression among Japanese employees threatened by job loss in a comparison between two complementary job-stress models. Scand J Work Environ Health 27:146-153

Vrijkotte TG, van Doornen LJ, Geus EJ (1999) Work stress and metabolic and hemostatic risk factors. Psychosom Med 61:796805

Williams RB (1987) Refining the type A hypothesis: emergence of the hostility complex. Am J Cardiol 60:27J-32J

Wojciechowski F, Strik J, Falger P, Lousberg R, Honig A (2000) The relationship between depressive and vital exhaustion symptomatology post-myocardial infarction. Acta Psychiatr Scand 102:359-365

Zigmond AS, Snaith RP (1983) The hospital anxiety and depression scale. Acta Psychiatr Scand 67:361-370 